\title{
Epidemiology and Clinical Characteristics of the First 500 Positive Cases of COVID-19. A Multicenter Retrospective Study across the Najran Region of the Kingdom of Saudi Arabia (KSA)
}

\author{
Hadi J. Al Sulayyim ${ }^{*}$, Mohammed Ch Al-Noaemi' ${ }^{2}$, Mohammed M. Alyami ${ }^{3}$, Shoab Ahmad ${ }^{1}$, \\ Mohammad H. Alyami ${ }^{4}$, Hamad S. Alyami ${ }^{4}$, Ali D. Al-Swedan'1, Ibraheem S. Banihameem', \\ Musallam A. Sedran'1, Ali M. Al-Zubaidi' ${ }^{1}$, Obaid M. Al Abbas ${ }^{1}$
}

${ }^{1}$ General Directorate of Health Affairs Najran, Ministry of Health, Najran, KSA

${ }^{2} \mathrm{Al}-$ Ghad International College of Applied Medical Sciences, Najran, KSA

${ }^{3}$ Batterjee Medical College, Jeddah, KSA

${ }^{4}$ Najran University, Najran, KSA

Email: ^hadialsleem@hotmail.com

How to cite this paper: Al Sulayyim, H.J., Al-Noaemi, M.Ch, Alyami, M.M., Ahmad, S., Alyami, M.H., Alyami, H.S., Al-Swedan, A.D., Banihameem, I.S., Sedran, M.A., Al-Zubaidi, A.M. and Al Abbas, O.M. (2021) Epidemiology and Clinical Characteristics of the First 500 Positive Cases of COVID-19. A Multicenter Retrospective Study across the Najran Region of the Kingdom of Saudi Arabia (KSA). Open Journal of Epidemiology, 11, 222-236. https://doi.org/10.4236/ojepi.2021.113019

Received: May 3, 2021

Accepted: June 25, 2021

Published: June 28, 2021

Copyright $\odot 2021$ by author(s) and Scientific Research Publishing Inc. This work is licensed under the Creative Commons Attribution International License (CC BY 4.0).

http://creativecommons.org/licenses/by/4.0/

\section{Abstract}

Introduction: Coronavirus Disease 2019 (COVID-19) is a viral infection that was first reported in Wuhan, China on 31 December 2019. This study aimed to clarify the epidemiology and clinical characteristics of 500 first COVID-19 in the Najran region, Saudi Arabia. Material and Methods: A multi-center retrospective study design was employed to study the first 500 confirmed COVID-19 positive cases in Najran province, Kingdom of Saudi Arabia (KSA). Data were collected from 1 March 2020 until 1 July 2020 and provided by the Infection Prevention and Control (IPC) department from the hospitals. Included cases were confirmed using real-time reverse transcriptase-polymerase chain reaction (RT-PCR). Demographic, vital signs, symptoms, incubation period, travel or exposure history medical history, and comorbidities were collected. Logistic regression analysis was used to explore the association between potential risk factors associated with symptoms occurrence of COVID-19. Results: The median age of 500 COVID-19 patients was 31 years; 333 (66.6\%) males. A total of 34 (6.8\%) were Healthcare Workers (HCWs). Out of the 500 patients, 180 (36\%) had at least one comorbid disease. The most common symptoms on admission were fever 281 (56.2\%), cough 266 (53.2\%), shortness of breath 166 (33.2\%), and malaise 113 (22.6\%). Most of the patients presented with mild disease severity 310 (62\%). Natio- 
nality, age, and Diabetes Miletus (DM) were independently and significantly associated with being symptomatic $(\mathrm{P}<0.05)$. Compared to Saudi nationals, other nationality patients were most likely to have symptoms $(\beta=2.968, \mathrm{CI}=$ $2.002-4.400, \mathrm{P}=0.0010)$. For every 1 year increase in age, the risk of being symptomatic increased by $5.8 \%(\beta=1.045, \mathrm{CI}=1.033-1.058, \mathrm{P}=0.001)$. Compared with non-DM patients, DM patients had a 4.05 times higher risk ( $\beta=4.05, \mathrm{CI}=2.188-7.507, \mathrm{P}=0.001)$ of getting symptoms. Conclusions: The study concluded that the majority of the COVID-19 patients were symptomatic or had mild disease severity. Age, nationality, and DM were the important risk factors in being symptomatic.

\section{Keywords}

Epidemiology, Characteristics, COVID-19, Najran, KSA

\section{Introduction}

In 1965, the first human coronavirus ( $\mathrm{HCoV}$ ) was identified by Tyrrell and Bynoe as they had isolated the virus from a nasal swab taken from a child patient [1]. By 1968, the term "Coronavirus" was endorsed for this group of viruses describing their unique characteristics [2].

HCoVs are enveloped viruses with a single-stranded, positive-sense RNA genome, approximately $30 \mathrm{~kb}$ in size, which is the largest known genome for RNA virus [3]. The genus "HCoV" belongs to the family of Coronaviridae in the order Nidovirales [3] [4] [5]. Moreover, HCoVs are widely distributed among birds, mammals, and humans [4] [5] [6] [7]. Dramatically, the earliest endemic of human $\mathrm{HCoV}$ dated back to the 1960s, when HCoV-OC43 and HCoV-229E were first reported [8] [9].

Around six species of HCoVs have been identified, that causes infections in human; 229E, OC43, NL63, and HKU1, and presenting symptoms are similar to the common cold [7] [10]. On the other hand, the other two species are considered zoonotic that provoke a severe acute respiratory syndrome (SARS-CoV), which was linked to the outbreak that occurred in Guangdong Province, the Republic of China in 2002 and 2003. SARS-CoV, may in some cases lead to systemic infection and eventually death (about 10\% of cases) [6] [11] [12] [13]. Another outbreak of coronavirus was notified in the Middle East, known as the Middle East respiratory syndrome coronavirus (MERS-CoV) [14] [15] [16].

On 31 December 2019, the local World Health Organization (WHO) office was alarmed with several pneumonia cases of etiology not known before, emerging in Wuhan, Hubei Province of China [17]. On 7 January 2020, the Chinese health authorities confirmed that this cluster was associated with a novel coronavirus, and it was called 2019-nCoV [18]. Subsequently, the task of experts of the International Committee on Taxonomy of Viruses named it severe acute respiratory syndrome coronavirus 2 (SARS-CoV-2) [19] owing to similari- 
ties to SARS-CoVs that caused the SARS outbreak in 2003. In February 2020, WHO named the disease caused by SARS-CoV-2 as COVID-19, which stands for coronavirus disease 2019 [20]. Further, on 11 March 2020, WHO declared COVID-19, a global pandemic [21].

Initial cases were proposed to be linked to a seafood wholesale market in Wuhan [22] [23]. Clinical presentation ranged from asymptomatic/mild symptoms to severe illness and death. The main symptoms are fever, cough, fatigue, shortness of breath, anorexia, and the presence of invasive lesions in bilateral lungs. Some patients may develop complete respiratory failure requiring intensive care for mechanical ventilation [24] [25] [26]. Evidence suggests that symptoms may develop 2 - 14 days after getting infected with the virus, and the mean incubation period, 5 days [27] [28] [29] [30].

The first case of COVID-19 in the KSA was reported on 2 March 2020 from Qatif, an eastern region through a Saudi citizen who had recently visited Iran. At the time Iran had already reported multiple cases of COVID-19. Further, the second case was reported on 4 March 2020 who had contact with the first case [31]. Concomitantly, until 27 June 2020, about 170,639 confirmed cases have been reported throughout KSA with 1428 deaths, as announced by the Saudi Ministry of Health (MOH) [32].

Since the introduction of COVID-19 in the Najran region and until 2 June 2020, there has been only one study that had evaluated the knowledge of HCWs about this new disease [33]. Therefore, this study aims to identify the epidemiology and clinical characteristics of the first 500 positive cases of COVID-19 in Najran province, KSA, and to explore the association of potential risk factors with symptoms occurrence of COVID-19.

\section{Material and Methods}

\subsection{Study Design and Participants}

This investigation employed a retrospective design study. The study included real-time reverse transcriptase-polymerase chain reaction (RT-PCR) confirmed COVID-19 cases from 13 different hospitals (public and private) across Najran province, KSA. Data collection had been undertaken from 1 March 2020 until 1 July 2020. Approval to conduct the study was granted by the Institutional Review Board at The General Directorate of Health Affairs, Najran (approval number 2020-07 E). Patients' eligibility to be included in the current study was determined through a confirmed positive COVID-19 test result and admission to one of the hospitals. COVID-19 test was done utilizing RT-PCR assay for a naso/oropharyngeal swab of COVID-19 suspected patients, as per the Saudi $\mathrm{MOH}$ guidelines [34]. A suspected case presented with one or more of the following symptoms; fever or history of fever, cough/dyspnea, and a travel history to known areas, currently identified as having an epidemic, or direct contact with a confirmed case of COVID-19.

In this study, we classified patients with COVID-19 as asymptomatic (a con- 
firmed case with no symptoms) and symptomatic (a confirmed case with symptoms). The severity of symptomatic cases was categorized as mild, moderate, severe, and critical as per the therapeutic protocol for COVID-19 patients issued by Saudi $\mathrm{MOH}$ (version 1.1). Disease severity was considered mild or moderate if mechanical ventilation was not required; while severe if the patient condition met at least one of the following criteria; respiratory distress with respiratory rate $\geq 30 / \mathrm{min}$, blood oxygen saturation $\left(\mathrm{SPO}_{2}\right) \leq 93 \%$ at rest, the arterial partial pressure of oxygen/inspired oxygen fraction ratio, $\left(\mathrm{PaO}_{2} / \mathrm{FiO}_{2}\right) \leq 300 \mathrm{~mm} \mathrm{Hg}$ and lung infiltration $>50 \%$ of the lung field within $24-48$ hours of admission. The case was classified as critical, if at least one or more symptoms of acute respiratory distress syndrome (ARDS), sepsis, altered consciousness, and multi-organ failure were present. Patient with cytokine release syndrome (criteria for patients at high risk for developing cytokine storm [ 1 or more of the following: Serum IL- $6 \geq 3 \mathrm{x}$ upper normal limit, Ferritin $>300 \mu \mathrm{g} / \mathrm{L}$ (or surrogate) with doubling within 24 hours, Ferritin $>600 \mu \mathrm{g} / \mathrm{L}$ at presentation and $\mathrm{LDH}>250$ and Elevated D-dimer $(>1 \mathrm{mcg} / \mathrm{mL})$ ].

\subsection{Data Collection}

For confirmation, a naso/oropharyngeal swab specimen was collected from all the suspected cases by a trained healthcare worker (HCW). Following collection, the specimens were sent to regional laboratories, either in Jeddah or Asir. The shipping condition of the samples was maintained by the carrier companies assuring the stability of the specimens during transportation. IPC department in each hospital had provided the patient data. The collected data included demographic, vital signs, clinical signs/symptoms, incubation period, travel or exposure history, etc.

\subsection{Statistical Analysis}

Statistical analysis was performed using the statistical packages IBMSPSS (version 20). Data in this study has been expressed as percentages (\%) and percentiles $\left(25^{\text {th }} \mathrm{Q} 1 \& 75^{\text {th }} \mathrm{Q} 3\right)$. Factors associated with being symptomatic were identified by using logistic regressions. The univariate model was used to find significant associative factors independently and later all the significant factors were analyzed collectively in a multivariate model. A probability $(\mathrm{P})$ value less than 0.05 was considered significant.

\section{Results}

A total of 500 COVID-19 positive cases were included in the study. The demographic and historical characteristics of cases are shown in Table 1. The median age of the cases was 31 years, and the majority were males 333 (66.6\%). Most of the cases were Saudi nationals 243 (48.6\%), followed by Yemenis 94 (18.8\%) while other nationalities included; Syrians and Indonesians at $6(0.6 \%)$ and 1 (0.2\%), respectively. About $34(6.8 \%)$ of cases were HCWs, 13 (2.6\%) were 
Table 1. Sociodemographic and historical characteristics of 500 positive COVID-19 cases in the Najran region, KSA.

\begin{tabular}{|c|c|c|c|}
\hline Variable & & $\mathbf{N}$ & $\%$ \\
\hline Age, Median (Q1 - Q3) & & 31 & $(23-40)$ \\
\hline \multirow{10}{*}{ Nationality } & Saudi & 243 & 48.6 \\
\hline & Yemeni & 94 & 18.8 \\
\hline & Bangladeshi & 43 & 8.6 \\
\hline & Indian & 58 & 11.6 \\
\hline & Pakistani & 14 & 2.8 \\
\hline & Indonesian & 1 & 0.2 \\
\hline & Egyptian & 23 & 4.6 \\
\hline & Sudanese & 11 & 2.2 \\
\hline & Syrian & 3 & 0.6 \\
\hline & Filipino & 10 & 2.0 \\
\hline \multirow{2}{*}{ Gender } & $\mathrm{F}$ & 167 & 33.4 \\
\hline & M & 333 & 66.6 \\
\hline \multirow{2}{*}{ HCW } & No & 466 & 93.2 \\
\hline & Yes & 34 & 6.8 \\
\hline \multirow{2}{*}{ Smoker } & No & 487 & 97.4 \\
\hline & Yes & 13 & 2.6 \\
\hline \multirow{2}{*}{ Diabetes Mellitus } & No & 398 & 79.6 \\
\hline & Yes & 102 & 20.4 \\
\hline \multirow{2}{*}{ Hypertension } & No & 434 & 86.8 \\
\hline & Yes & 66 & 13.2 \\
\hline \multirow{2}{*}{ Allergies } & No & 496 & 99.2 \\
\hline & Yes & 4 & 0.8 \\
\hline \multirow{2}{*}{ Pulmonary Disease } & No & 491 & 98.2 \\
\hline & Yes & 9 & 1.8 \\
\hline \multirow{2}{*}{ Pregnancy } & No & 493 & 98.6 \\
\hline & Yes & 7 & 1.4 \\
\hline \multirow{2}{*}{ Cardiovascular diseases } & No & 498 & 99.6 \\
\hline & Yes & 2 & 0.4 \\
\hline \multirow{2}{*}{ Kidney Disease } & No & 499 & 99.8 \\
\hline & Yes & 1 & 0.2 \\
\hline Central Nervous disease & No & 500 & 100 \\
\hline Liver Disease & No & 500 & 100 \\
\hline Tuberculosis & No & 500 & 100 \\
\hline
\end{tabular}

Q1: First quartile; Q3: Third quartile. 
smokers, and $7(1.4 \%)$ were pregnant. The most common comorbid diseases were Diabetes Miletus 102 (DM 20.4\%) hypertension 66 (HTN 13.2\%), and chronic pulmonary disease 9 (1.8\%).

Table 2 demonstrates the clinical presentation of the cases included in the study. Approximately 339 (67.8\%) of the patients were admitted to a hospital with symptoms. The most common symptoms on admission were fever 281 (56.2\%), cough 266 (53.2\%), shortness of breath 166 (33.2\%), and malaise 113 (22.6\%). Interestingly, vital signs for most of the patients were near normal. The mean temperature of the patients was $37^{\circ} \mathrm{C}(98.6 \mathrm{~F})$, pulse rate 85 per min, respiratory rate 22 per min, blood pressure $126 / 79 \mathrm{~mm} \mathrm{hg}$ (systolic/diastolic), and the mean $\mathrm{SPO}_{2} 96 \%$.

In terms of the clinical course of the COVID-19, Figure 1 displays the median incubation period, which was 5 days $(4-6)$. The median of the symptomatic period was 4 days ( 3 - 6), the latent period was 4 days ( 3 - 5) while the median of the positivity period was 11 days $(9-14)$.

From Figure 2, the analysis of disease severity showed that the majority 310 (62\%) of the cases presented with mild disease. Roughly, 160 (32\%) of patients reported moderate disease, and only a small minority 20 and 10 (4\% and 2\%) of the cases presented with severe and critical disease, respectively.

Factors associated with being symptomatic are presented in Table 3. According to logistic regression, in univariate analysis, nationality, age, and DM were significantly associated factors $(\mathrm{P}<0.05)$. In multivariate analysis, nationality,

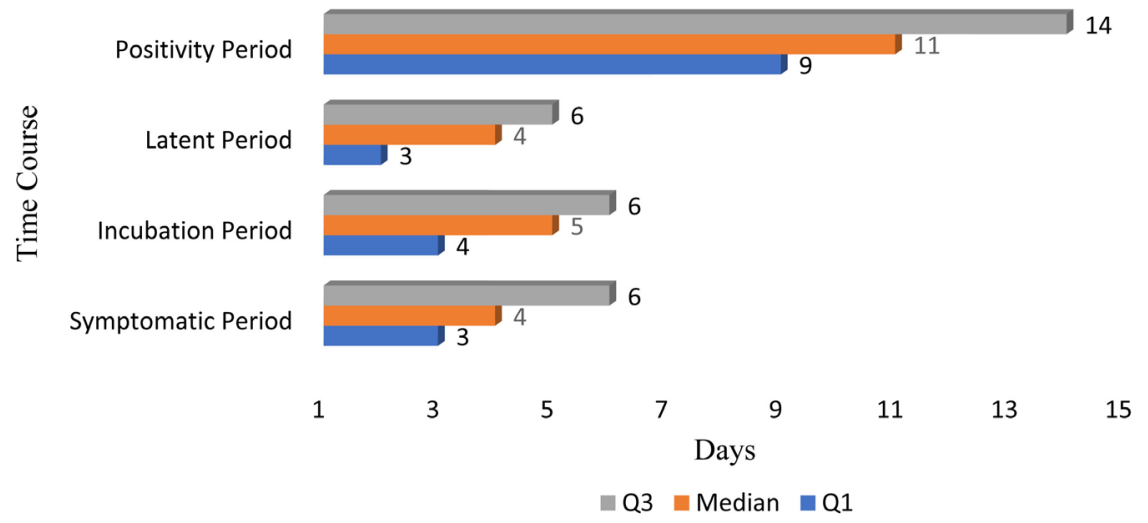

Figure 1. Time course of COVID-19 for 500 positive cases in Najran, KSA.

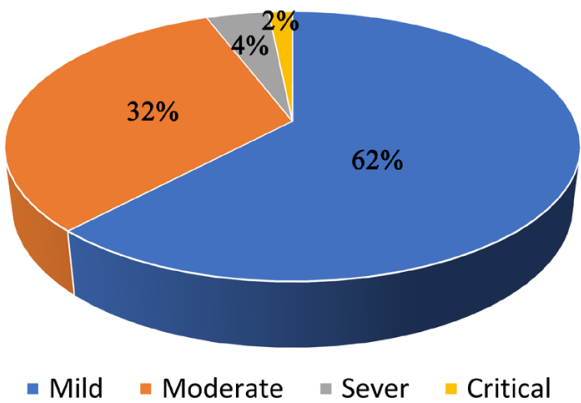

Figure 2. Case severity of 500 COVID-19 positive cases in Najran, KSA. 
Table 2. Clinical presentation of 500 positive COVID-19 cases in the Najran region, KSA.

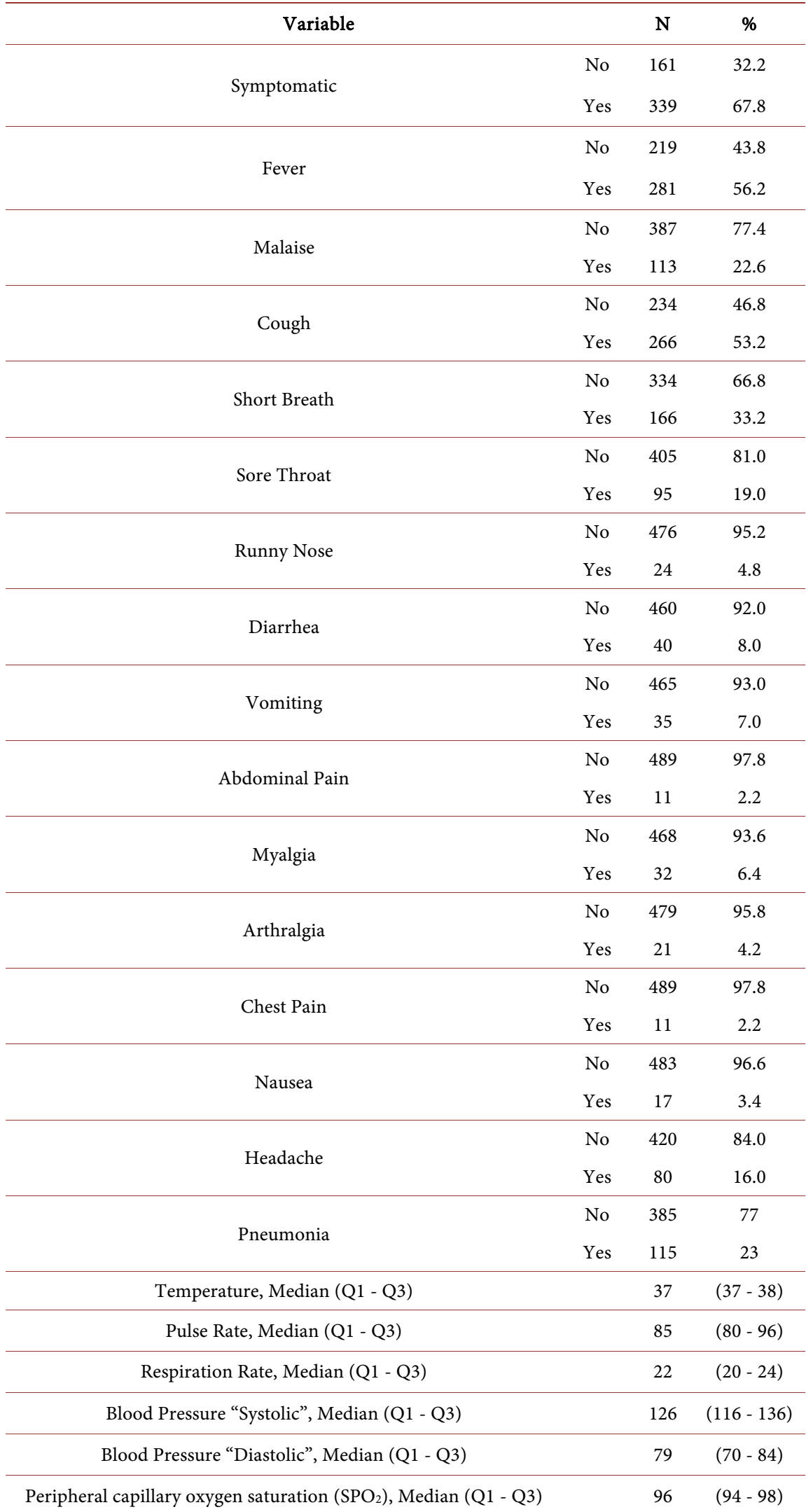

Q1: First quartile; Q3: Third quartile. 
Table 3. Factors associated with symptomatic patients.

\begin{tabular}{|c|c|c|c|c|c|}
\hline \multirow{2}{*}{ Factor } & \multirow{2}{*}{$\mathrm{N}(\%)$} & Univariate analysis & \multirow{2}{*}{$\mathrm{P}$} & Multivariate analysis & \multirow{2}{*}{$\mathrm{P}$} \\
\hline & & OR $(95 \% \mathrm{CI})$ & & OR $(95 \% \mathrm{CI})$ & \\
\hline \multicolumn{6}{|l|}{ Nationality } \\
\hline Non Saudi & $254(49.2)$ & $2.968(2.002-4.400)$ & $0.001^{*}$ & $2.755(1.77-4.221)$ & $0.001^{\star}$ \\
\hline Saudi & $246(50.8)$ & 1 & & 1 & \\
\hline Age & & $1.045(1.033-1.058)$ & $0.001^{*}$ & $1.035(1.023-1.048)$ & $0.001^{*}$ \\
\hline \multicolumn{6}{|c|}{ Chronic Diseases } \\
\hline $\mathrm{DM}$ & $102(40.4)$ & $4.05(2.188-7.507)$ & $0.001^{\star}$ & $3.238(1.667-6.253)$ & $0.001^{*}$ \\
\hline Non-DM & $398(79.6)$ & 1 & & 1 & \\
\hline
\end{tabular}

DM: Diabetes mellitus; CI: Confidence Interval; OR: Odds Ratio *Signiant at 0.05 .

age, and DM were also independently significantly associated with the appearance of the symptoms $(\mathrm{P}<0.05)$. Compared to Saudi nationals, other nationality patients were most likely to have symptoms $(\beta=2.968, \mathrm{CI}=2.002-4.400, \mathrm{P}=$ $0.001)$. For every 1 year increase in age, the risk of developing symptoms increased by $5.8 \%(\beta=1.045, \mathrm{CI}=1.033-1.058, \mathrm{P}=0.001)$. Compared with non-DM patients, DM patients had 4.05 times higher risk $(\beta=4.05, \mathrm{CI}=2.188$ $7.507, \mathrm{P}=0.001)$ of getting symptoms.

\section{Discussion}

Early identification studies, via next-generation sequencing and culture isolates of respiratory tract samples, have revealed that the genome of SARS-CoV-2 is $79 \%$ and $50 \%$ identical to SARS-CoV and MERS-CoV respectively [35]. Data from the epidemiological, clinical characteristics and therapeutic outcomes of patients of COVID-19 need an evaluation. To the best of our knowledge, the current study is the first to investigate the epidemiological and clinical characteristics of 500 patients with COVID-19 in the south region of the KSA.

Since the introduction and until 1 June 2020, 137 cases were reported by the appropriate authorities in the Najran region. But there had been an exponential increase in the number of cases since lockdown measures were removed and as of June 26, 2020, a total of 881 cases have been reported.

Similar to previously published studies, the findings in this study indicate the high contagiousness of this novel virus either via direct or indirect contact [29] [36] [37]. Nearly all of the patients included in the study had no recent travel history (Table 1). Of all the patients, 339 (67.8\%) were symptomatic; fever 281 (56.2\%), malaise 113 (22.6\%), and cough 266 (53.2\%), and these were the most common presenting symptoms. Other symptoms such as shortness of breath, nausea/vomiting, abdominal pain, and diarrhea were not very common in this study. Further, at the time of admission 161 (32.2\%) patients were asymptomatic. Therefore, a comprehensive assessment of the patient's condition is crucial to avoid a missed diagnosis. Results in this study are uniform with several other 
published studies that have highlighted the epidemiological and clinical characteristics of COVID-19 [24] [38].

Further, the study confirms that people from all age groups are equally susceptible to the COVID-19 infection, with a median age of 31 years in this study. Infection was more common in males $(\mathrm{N}=333,66.6 \%)$ compared to females $(\mathrm{N}$ $=167,33.4 \%)$ and this trend has been reported previously in many published studies [29] [36] [37] [39]. This might be due to differences among males and females rooted in their anatomy, physiology, biochemistry, genetics, and lifestyle, specifically with the increased pieces of evidence concerning health and health outcomes [40]. For example, men tend to use all tobacco products at higher rates than women [41], smoking may help increase the expression of angiotensin-converting enzyme 2 in lung tissue, which plays a key role in SARS-CoV-2 infection [42] [43]. This might also explain the higher number of infections among middle or elderly-aged males who are more likely to be smokers. Of all cases, 34 (6.8\%) were HCWs, which supports the rapid transmissibility of the novel disease across health care settings [42].

The presence of other comorbid diseases was found to be important risk factors for COVID-19. According to the latest reports, the clinical manifestations of COVID-19 are heterogeneous [36] [44] [45] [46] [47], e.g., 20\% - 51\% of patients reported having at least one comorbidity on admission, with DM (10\% $20 \%)$, HTN (10\% - 15\%), and other cardiovascular and cerebrovascular diseases (7\% - 40\%) being most common [3] [46] [47].

Our findings disclosed similar comorbid conditions compared to the other published results i.e. DM (20.4\%) and HTN (13.2\%), followed by $2.6 \%$ for allergies and pulmonary disease each. 2 females were pregnant in this study but the outcome could not be evaluated as the expected date of delivery was beyond the current study period.

The clinical manifestations of COVID-19 in this study were wide-ranged, from being asymptomatic to mild or severe. At $<4 \%$ severe cases and $32 \%$ moderate cases, the findings (Figure 2) indicate that the case severity was not as much of what has been described in published literature elsewhere (severity > 20\%) [44].

This significant finding may be attributable to the health outcomes, the lifestyle of the population in the Najran region, the geography of the region itself as a desert mountainous hot area, or other factors that need further evaluation. Yet, patients from all age groups are equally vulnerable even in the absence of any comorbidity. There were two deaths reported but the exact cause of death remains uncertain. One was 20 years old Saudi national with a chest infection at the time of admission with no other underlying health condition and the other was 51 years old asymptomatic Yemeni national. This study demonstrates an association between the presence of COVID-19 symptoms and DM. This association indicates that DM may independently contribute to an increase in the susceptibility of COVID-19 in patients with DM. This finding is corresponding to 
previously reported work found that people with DM at greater risk of COVID-19 [1] [2] [3].

Although other published studies advise that the presence of any comorbidity may increase the risk of developing ARDS especially in patients with H7N9, influenza, SARS-CoV, MERS-CoV, and SARS-CoV-2 infection [24] [36] [44] [48], Patients with any comorbidity yield poorer clinical outcomes than those without any [19] [44].

Interestingly, our study revealed that people from other nationalities developed symptoms at a higher frequency than Saudi nationals, which might be interpreted to the immunity acquired previously from MERS-CoV but it needs further evaluation [48]. Gender, nationality, and health status can pose both a challenge and an opportunity during the outbreak, as well as potent predictors for disease risk [49] [50].

Results revealed the median time between known exposure and becoming infected was around 4 days. While the median duration from onset of symptoms to admission to a hospital was 4 days and the incubation period median was 5 days, which is in agreement with existing results elsewhere [24] [38].

\section{Strengths and Limitations}

Nonetheless, our study had certain limitations, specifically in study design. First, we could include only 500 confirmed cases, which are relatively small sample size. Second, the issue of recall bias could not have been eliminated, with patients giving inaccurate information on the date/mode of exposure or travel or onset of symptoms and their identification. The strengths of this study include detailed demographical data and clinical presentation of cases, and the use of multivariate analyses to identify the fundamental factors associated with the existence of symptoms. Novel findings of the study included confirmation of the risk factors among specific gender, age groups, and nationalities.

\section{Conclusion}

The most frequent symptoms in the study were fever, cough, short breath, and malaise. The severity of the disease was low in the Najran region, which requires further evaluation. Age, nationality, and DM were found as the main risk factors linked with SARS-CoV-2 symptomatic infection in the Najran region. Further studies are needed to explore the reasons behind the low severity of COVID-19 infection in the Najran region, KSA.

\section{Acknowledgements}

We are thankful to all the hospitals in the Najran region for cooperation and facilitation of the data collection.

\section{Ethical Approval}

This study was approved by the Institutional Review Board at The General Di- 
rectorate of Health Affairs, Najran (approval number 2020-07 E).

\section{Availability of Data and Material}

The data will be available when it's needed.

\section{Conflicts of Interest}

None of the authors have any conflict of interest.

\section{References}

[1] Tyrrell, D.A.J. and Bynoe, M.L. (1965) Cultivation of a Novel Type of Common Cold Virus in Organ Culture. The BMJ, 1, 1467.

https://doi.org/10.1136/bmj.1.5448.1467

[2] Tyrrell, D.A.J., Almeida, J., Berry, D.M., Cunningham, H., Hamre, D., Hofstad, M.S., et al. (1968) Coronaviruses. Nature, 220, 650. https://doi.org/10.1038/220650b0

[3] Weiss, S.R. and Navas-Martin, S. (2005) Coronavirus Pathogenesis and the Emerging Pathogen Severe Acute Respiratory Syndrome Coronavirus. Microbiology and Molecular Biology Reviews, 69, 635-664. https://doi.org/10.1128/MMBR.69.4.635-664.2005

[4] Keyaerts, E., Li, S., Vijgen, L., Rysman, E., Verbeeck, J., et al. (2009) Antiviral Activity of Chloroquine against Human Coronavirus OC43 Infection in Newborn Mice. Antimicrobial Agents and Chemotherapy, 53, 3416-3421. https://doi.org/10.1128/AAC.01509-08

[5] Corman, V.M., Muth, D., Niemeyer, D. and Drosten, C. (2018) Hosts and Sources of Endemic Human Coronaviruses. Advances in Virus Research, 100, 163-188. https://doi.org/10.1016/bs.aivir.2018.01.001

[6] Zhong, N.S., Zheng, B.J., Li, Y.M., Poon, L.L., Xie, Z.H., Chan, K.H., et al. (2003) Epidemiology and Cause of Severe Acute Respiratory Syndrome (SARS) in Guangdong, People's Republic of China, in February 2003. The Lancet, 362, 1353-1358. https://doi.org/10.1016/S0140-6736(03)14630-2

[7] Cui, J., Li, F. and Shi, Z.L. (2019) Origin and Evolution of Pathogenic Coronaviruses. Nature Reviews Microbiology, 17, 181-192. https://doi.org/10.1038/s41579-018-0118-9

[8] Hamre, D. and Procknow, J.J. (1966) A New Virus Isolated from the Human Respiratory Tract. Proceedings of the Society for Experimental Biology and Medicine, 121, 190-193. https://doi.org/10.3181/00379727-121-30734

[9] McIntosh, K., Dees, J.H., Becker, W.B., Kapikian, A.Z. and Chanock, R.M. (1967) Recovery in Tracheal Organ Cultures of Novel Viruses from Patients with Respiratory Disease. Proceedings of the National Academy of Sciences of the United States of America, 57, 933-940. https://doi.org/10.1073/pnas.57.4.933

[10] Su, S., Wong, G., Shi, W., Liu, J., Lai, A.C., Zhou, J., et al. (2016) Epidemiology, Genetic Recombination, and Pathogenesis of Coronaviruses. Trends in Microbiology, 24, 490-502. https://doi.org/10.1016/j.tim.2016.03.003

[11] Drosten, C., Günther, S., Preiser, W., Van Der Werf, S., Brodt, H.R., Becker, S., et al. (2003) Identification of a Novel Coronavirus in Patients with the Severe Acute Respiratory Syndrome. New England Journal of Medicine, 348, 1967-1976.

https://doi.org/10.1056/NEJMoa030747 
[12] Ksiazek, T.G., Erdman, D., Goldsmith, C.S., Zaki, S.R., Peret, T., Emery, T.S., et al. (2003) A Novel Coronavirus Associated with the Severe Acute Respiratory Syndrome. The New England Journal of Medicine, 348, 1953-1966. https://doi.org/10.1056/NEJMoa030781

[13] Cyranoski, D. (2003) China Joins Investigation of Mystery Pneumonia. Nature, 422 459. https://doi.org/10.1038/422459b

[14] Zaki, A.M., van Boheemen, S., Bestebroer, T.M., Osterhaus, A.D. and Fouchier, R.A. (2012) Isolation of a Novel Coronavirus from a Man with Pneumonia in Saudi Arabia. The New England Journal of Medicine, 367, 1814-1820. https://doi.org/10.1056/NEJMoa1211721

[15] Assiri, A., Al-Tawfiq, J.A., Al-Rabeeah, A.A., Al-Rabiah, F.A., Al-Hajjar, S., Al-Barrak, A., et al. (2013) Epidemiological, Demographic, and Clinical Characteristics of 47 Cases of Middle East Respiratory Syndrome Coronavirus Disease from Saudi Arabia: A Descriptive Study. The Lancet Infectious Diseases, 13, 752-761. https://doi.org/10.1016/S1473-3099(13)70204-4

[16] Zumla, A., Hui, D.S. and Perlman, S. (2015) Middle East Respiratory Syndrome. The Lancet, 386, 995-1007. https://doi.org/10.1016/S0140-6736(15)60454-8

[17] WHO (2020) Pneumonia of Unknown Cause-China. Disease Outbreak News, 5 January.

https://www.who.int/csr/don/05-january-2020-pneumonia-of-unkown-cause-china len

[18] World Health Organization (2020) Novel Coronavirus-China. https://www.who.int/csr/don/12-january-2020-novel-coronavirus-china/en

[19] Gorbalenya, A.E., Baker, S.C., Baric, R.S., de Groot, R.J., Drosten, C., Gulyaeva, A.A., et al. (2020) Severe Acute Respiratory Syndrome-Related Coronavirus: The Species and Its Viruses-A Statement of the Coronavirus Study Group. https://www.biorxiv.org/content/10.1101/2020.02.07.937862v1 https://doi.org/10.1101/2020.02.07.937862

[20] World Health Organization (2020) Director-General's Remarks at the Media Briefing on 2019-nCoV on 11 February 2020.

https://www.who.int/dg/speeches/detail/who-director-general-s-remarks-at-the-me dia-briefing-on-2019-ncov-on-11-february-2020

[21] Ghebreyesus, T.A. (2020) Director-General of the WHO Announces That the COVID-19 Outbreak Is a Pandemic.

[22] Wuhan City Health Committee (WCHC) (2019) Wuhan Municipal Health and Health Commission's Briefing on the Current Pneumonia Epidemic Situation in Our City 2019. http://wjw.wuhan.gov.cn/front/web/showDetail/2019123108989

[23] Mackenzie, J.S. and Smith, D.W. (2020) COVID-19: A Novel Zoonotic Disease Caused by a Coronavirus from China: What We Know and What We Don't. Microbiology Australia, 41, 45-50. https://doi.org/10.1071/MA20013

[24] Huang, C., Wang, Y., Li, X., Ren, L., Zhao, J., Hu, Y., et al. (2020) Clinical Features of Patients Infected with 2019 Novel Coronavirus in Wuhan, China. The Lancet, 395, 497-506. https://doi.org/10.1016/S0140-6736(20)30183-5

[25] Wang, D., Hu, B., Hu, C., Zhu, F., Liu, X., Zhang, J., et al. (2020) Clinical Characteristics of 138 Hospitalized Patients with 2019 Novel Coronavirus-Infected Pneumonia in Wuhan, China. Journal of the American Medical Association, 323, 1061-1069. https://doi.org/10.1001/jama.2020.1585

[26] Siordia Jr., J.A. (2020) Epidemiology and Clinical Features of COVID-19: A Review of Current. Journal of Clinical Virology, 127, Article ID: 104357. 
https://doi.org/10.1016/j.jcv.2020.104357

[27] Lauer, S.A., Grantz, K.H., Bi, Q., Jones, F.K., Zheng, Q., Meredith, H.R., et al. (2020) The Incubation Period of Coronavirus Disease 2019 (COVID-19) from Publicly Reported Confirmed Cases: Estimation and Application. Annals of Internal Medicine, 172, 577-582. https://doi.org/10.7326/M20-0504

[28] Backer, J.A., Klinkenberg, D. and Wallinga, J. (2020) Incubation Period of 2019 Novel Coronavirus (2019-nCoV) Infections among Travellers from Wuhan, China, 20-28 January 2020. Eurosurveillance, 25, Article ID: 2000062. https://doi.org/10.2807/1560-7917.ES.2020.25.5.2000062

[29] Li, Q., Guan, X., Wu, P., Wang, X., Zhou, L., Tong, Y., et al. (2020) Early Transmission Dynamics in Wuhan, China, of Novel Coronavirus-Infected Pneumonia. The New England Journal of Medicine, 382, 1199-1207.

https://doi.org/10.1056/NEJMoa2001316

[30] Linton, N.M., Kobayashi, T., Yang, Y., Hayashi, K., Akhmetzhanov, A.R., Jung, S.M., et al. (2020) Incubation Period and Other Epidemiological Characteristics of 2019 Novel Coronavirus Infections with Right Truncation: A Statistical Analysis of Publicly Available Case Data. Journal of Clinical Medicine, 9, 538. https://doi.org/10.3390/jcm9020538

[31] Saudi Arabia Announces First Case of Coronavirus. Arabnews.com. 2 March 2020. https://www.arabnews.com/node/1635781/saudi-arabia

[32] Saudi Arabia's Health Ministry. COVID 19 Dashboard: Saudi Arabia. https://covid19.moh.gov.sa

[33] Al Sulayyim, H., Al-Noaemi, M., Rajab, S., Daghriri, H., Al Yami, S., Al-Rashah, A., et al. (2020) An Assessment of Healthcare Workers Knowledge about COVID-19. Open Journal of Epidemiology, 10, 220-234. https://doi.org/10.4236/ojepi.2020.103020

[34] Saudi Center for Disease Prevention and Control. Coronavirus Disease 19 (COVID-19) Guidelines February 2020 V1.1.

https://www.moh.gov.sa/CCC/healthp/regulations/Documents/Coronavirus\%20Dis ease\%202019\%20Guidelines\%20v1.1..pdf

[35] Wang, R., Pan, M., Zhang, X., Han, M., Fan, X., Zhao, F., et al. (2020) Epidemiological and Clinical Features of 125 Hospitalized Patients with COVID-19 in Fuyang, Anhui, China. International Journal of Infectious Diseases, 95, 421-428. https://doi.org/10.1016/j.ijid.2020.03.070

[36] Chen, N., Zhou, M., Dong, X., Qu, J., Gong, F., Han, Y., et al. (2020) Epidemiological and Clinical Characteristics of 99 Cases of 2019 Novel Coronavirus Pneumonia in Wuhan, China: A Descriptive Study. The Lancet, 395, 507-513. https://doi.org/10.1016/S0140-6736(20)30211-7

[37] Nikpouraghdam, M., Farahani, F.A., Alishiri, G.H., Heydari, S., Ebrahimnia, M., Samadinia, H., et al. (2020) Epidemiological Characteristics of Coronavirus Disease 2019 (COVID-19) Patients in IRAN: A Single Center Study. Journal of Clinical Virology, 127, Article ID: 104378. https://doi.org/10.1016/j.jcv.2020.104378

[38] Xia, W., Shao, J., Guo, Y., Peng, X., Li, Z. and Hu, D. (2020) Clinical and CT Features in Pediatric Patients with COVID-19 Infection: Different Points from Adults. Pediatric Pulmonology, 55, 1169-1174. https://doi.org/10.1002/ppul.24718

[39] Li, Q., Guan, X., Wu, P., Wang, X., Zhou, L., Tong, Y., et al. (2020) Early Transmission Dynamics in Wuhan, China, of Novel Coronavirus-Infected Pneumonia. The New England Journal of Medicine, 382, 1199-1207. https://doi.org/10.1056/NEJMoa2001316 
[40] Bainham, A. (2002) Exploring the Biological Contributions to Human Health: Does Sex Matter? Cambridge Law Journal, 61, 1-52. https://doi.org/10.1017/S0008197302361506

[41] NIDA (2020) Tobacco, Nicotine, and E-Cigarettes Research Report. https://www.drugabuse.gov/download/1344/tobacco-nicotine-e-cigarettes-researchreport.pdf? $v=2 \mathrm{af} 15 \mathrm{ced} 378 \mathrm{ee} 345 \mathrm{c} 81758 \mathrm{ed} 06 \mathrm{a} 4 \mathrm{cc} 27$

[42] Xu, X., Chen, P., Wang, J., Feng, J., Zhou, H., Li, X., et al. (2020) Evolution of the Novel Coronavirus from the Ongoing Wuhan Outbreak and Modeling of Its Spike Protein for Risk of Human Transmission. Science China Life Sciences, 63, 457-460. https://doi.org/10.1007/s11427-020-1637-5

[43] Cai, G. (2020) Bulk and Single-Cell Transcriptomics Identify Tobacco-Use Disparity in Lung Gene Expression of ACE2, the Receptor of 2019-nCov.

https://doi.org/10.20944/preprints202002.0051.v2

[44] Guan, W.J., Liang, W.H., Zhao, Y., Liang, H.R., Chen, Z.S., Li, Y.M., et al. (2020) Comorbidity and Its Impact on 1,590 Patients with Covid-19 in China: A Nationwide Analysis. European Respiratory Journal, 55, Article ID: 2000547. https://doi.org/10.1183/13993003.01227-2020

[45] Zhang, S., Li, H., Huang, S., You, W. and Sun, H. (2020) High-Resolution Computed Tomography Features of 17 Cases of Coronavirus Disease 2019 in Sichuan Province, China. European Respiratory Journal, 55, 2019-2021. https://doi.org/10.1183/13993003.00334-2020

[46] Xu, X.W., Wu, X.X., Jiang, X.G., Xu, K.J., Ying, L.J., Ma, C.L., et al. (2020) Clinical Findings in a Group of Patients Infected with the 2019 Novel Coronavirus (SARS-Cov-2) outside of Wuhan, China: Retrospective Case Series. BMJ, 368, m792.

[47] Liu, K., Fang, Y.Y., Deng, Y., Liu, W., Wang, M.F., Ma, J.P., et al. (2020) Clinical Characteristics of Novel Coronavirus Cases in Tertiary Hospitals in Hubei Province. Chinese Medical Journal, 133, 1025-1031. https://doi.org/10.1097/CM9.0000000000000744

[48] Al Sulayyim, H.J., Khorshid, S.M. and Al Moummar, S.H. (2020) Demographic, Clinical, and Outcomes of Confirmed Cases of Middle East Respiratory Syndrome Coronavirus (MERS-CoV) in Najran, Kingdom of Saudi Arabia (KSA); a Retrospective Record Based Study. Journal of Infection and Public Health, 13, 1342-1346. https://doi.org/10.1016/j.jiph.2020.04.007

[49] Cummings, M.J., Baldwin, M.R., Abrams, D., Jacobson, S.D., Meyer, B.J., Balough, E.M., et al. (2020) Epidemiology, Clinical Course, and Outcomes of Critically Ill Adults with COVID-19 in New York City: A Prospective Cohort Study. The Lancet, 395, 1763-1770. https://doi.org/10.1016/S0140-6736(20)31189-2

[50] Guan, W.J., Ni, Z.Y., Hu, Y., Liang, W.H., Ou, C.Q., He, J.X., Liu, L., Shan, H., Lei, C.L., Hui, D.S. and Du, B. (2020) Clinical Characteristics of Coronavirus Disease 2019 in China. New England Journal of Medicine, 382, 1708-1720.

https://doi.org/10.1056/NEJMoa2002032 


\section{Abbreviation}

COVID-19: Coronavirus Disease 2019

HCoV: Human Coronavirus

SARS-CoV: Severe Acute Respiratory Syndrome

MERS-CoV: Middle East Respiratory Syndrome Coronavirus

WHO: World Health Organization

KSA: Kingdom of Saudi Arabia

MOH: Ministry of Health

HCW: HealthCare Worker

RT-PCR: Reverse Transcriptase-Polymerase Chain Reaction

IPC: Infection Prevention and Control

P: Probability

DM: Diabetes Miletus

HTN: Hypertension

$\mathrm{SPO}_{2}$ : Peripheral Capillary Blood Oxygen Saturation 